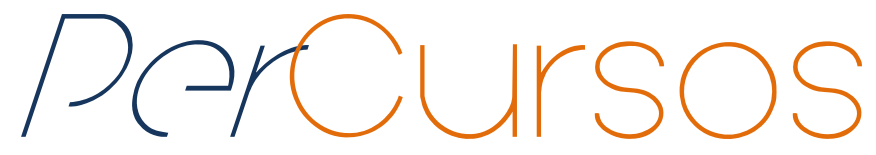

\title{
Resenha do livro \\ "The Maya Forest Garden: Eight Millenia of Sustainable Cultivation of the tropical Woodlands"
}

FORD, Anabel; NIGH, Ronald Nigh-Waulnut. The Maya Forest Garden: Eight Millenia of Sustainable Cultivation of the tropical Woodlands. -CA, Left Coast Press, INC, 2015. 260 p.

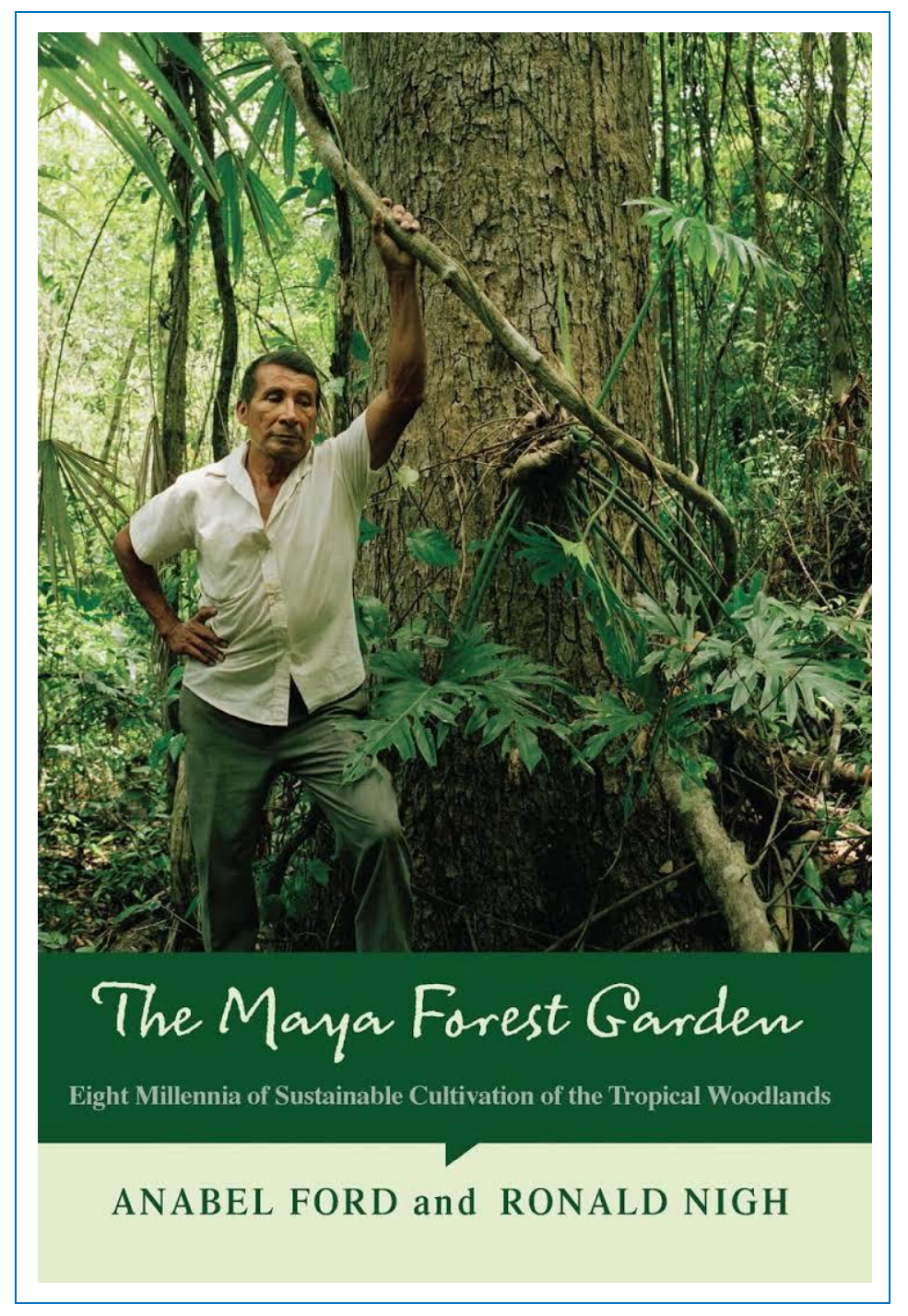

\section{Autores da resenha}

Daniel Montenegro Lapola Mestrando no Programa de PósGraduação Sociedade e Fronteiras na Univ. Federal de Roraima - UFRR.

Graduado em História pela Universidade Estadual Paulista UNESP/Assis-SP. Brasil

danielmontenegro78@gmail.com

\section{Maxim Repetto}

Doutor em Antropologia Social pela Universidade de Brasília - UNB.

Professor da Universidade Federal de Roraima -UFRR. Brasil

maxim.repetto@yahoo.com.br

\section{Para citar esta resenha:}

LAPOLA, Daniel Montenegro; REPETTO, Maxim. Resenha do livro “The Maya Forest Garden: Eight Millenia of Sustainable Cultivation of the tropical Woodlands”. Revista PerCursos. Florianópolis, v. 19, n. 39, p. 229 - 233, jan./abr. 2018.

\section{DOI: $10.5965 / 1984724619392018229$}

http://dx.doi.org/10.5965/1984724619392018229 
Os autores deste livro são Anabel Ford, arqueóloga com foco de estudo em assentamento e ambiente, diretora do Centro de Pesquisa da Universidade da Califórnia, Santa Barbara, e Ronald Nigh, etnógrafo com foco de estudo em agroecologia e etnobotânica, professor de Antropologia no Centro de Pesquisas e Estudos Superiores em Antropologia Social, CIESAS- Chiapas, México. Este livro deve muito em sua inspiração ao Jardim Florestal Maia de Belize, Guatemala e México, onde os indígenas maias desenvolveram sua sabedoria tradicional no manejo da floresta.

Ambos os pesquisadores têm passado suas carreiras estudando os conhecimentos tradicionais dos índios maias através do relacionamento deles com a conservação de seu ambiente e de suas visões e concepções sobre a floresta. Utilizam-se também de métodos estatísticos, mapas e fotos de satélite e levam em conta o impacto climático do local estudado.

O livro demonstra não só a possibilidade, mas também a problemática que o sistema maia da roça (milpa) suscita, uma vez que se trata de uma policultura agroflorestal diversificada, que forma um verdadeiro "jardim florestal maia”, o qual ainda hoje é muito útil e ativo e pode ser visto como uma estratégia de sustentabilidade da civilização maia. Essa estratégia era praticada no período clássico, nos anos 500 a 900 D.C., e suportou a conquista dos espanhóis a partir de 1524.

Pensando a floresta maia, o livro trata do problema da compatibilidade da agricultura e da floresta, comparando o sistema de roça maia ao sistema agrícola europeu de campo arado e pastagem. Este sistema tradicional de roça, como qualquer sistema agrícola, perturba o ambiente natural, mas os autores mostram como pode ser trabalhado em uma floresta tropical densa de forma integral, permitindo a recuperação e a sustentabilidade.

Tratam também sobre o uso manipulado da história maia contada pelos espanhóis, os quais elaboraram uma versão desta história como se tivesse ocorrido um esvaziamento das cidades dos maias e uma crise alimentar. Na visão dos autores do presente livro, o que ocorreu foi um deslocamento migratório para as terras baixas da floresta, a partir do qual houve uma consolidação dos valores de conservação, através da 
prática da roça de sustentabilidade e do manejo agroflorestal, o que desmascara a visão de que os maias praticamente tivessem sido extintos.

Os pesquisadores chamam a atenção sobre o interesse da propriedade privada em converter a floresta em pasto, o qual é um sistema mais degradante do meio ambiente. Portanto, é fundamental compreender e utilizar a visão maia, pois é um sistema de agricultura indígena coletivo, que há muito tempo integra os ciclos das roças às suas atividades domésticas e ao manejo das florestas. O sistema maia, em tempos de crescimento da população, intensificou o uso das terras, envolvendo investimento em conhecimento, habilidade e trabalho.

Os autores apresentam a sabedoria histórica dos maias, discutindo a relação da população com a terra, com os ciclos de roças, com as novas descobertas tecnológicas, com fatores políticos e com diversos processos sociais. Dessa forma refletem como as “formas" ou "técnicas" "tradicionais" de manejo maia nos dias de hoje se relacionam com os relatos cronológicos da antiguidade maia.

Os autores tratam a capacidade produtiva e a complexidade da roça e seu jardim florestal relacionando-o com um sistema mais amplo, que envolve os grandes valores agrícolas ecológicos e a notável diversidade de recursos domésticos deste povo. Dessa forma, se faz possível o manejo da terra, em um sistema que combina a realização de culturas anuais e o reaproveitamento por parte da floresta dos restos de superfície orgânica carbonada queimada nas roças. Estes restos de carvão permaneceram na terra após a preparação dos plantios, o que realça o solo e a biodiversidade da floresta em recomposição.

O livro apresenta um estudo centrado na geografia e na arqueologia da área do importante centro clássico da cidade de El Pilar, localizada na Guatemala, na fronteira com Belize. Estudando as características ambientais e os padrões de assentamento, estimando a população e modelando o sistema de roça maia em aproximadamente 1300 km quadrados, conseguiram determinar o grande potencial do ciclo do "jardim florestal" da roça, através do rendimento das plantações de milho que ajudam a sustentar uma densa população nesta área e a cobrir mais do que suas necessidades. 
O trabalho evidencia que o desmatamento tem sido amplamente proposto por estudiosos da história maia, como uma explicação para o declínio maia no período pósclássico, há aproximadamente 1000 anos. Isso pressupõe, no entanto, que a paisagem tropical limita o desenvolvimento da civilização e que o sistema de roça, tão primitivo, não pode suportar uma ampla população. Porém, dada à sofisticação do sistema da roça maia, do cuidado com a cobertura vegetal da terra que modera os caprichos das chuvas e a complexidade do sistema de subsistência, podemos ver que as florestas gerenciadas são parte integrante da roça e vice versa.

O estudo é concluído com considerações sobre o futuro da floresta maia. Mostram o desenvolvimento dos maias e suas florestas e consideram como a gestão baseada na habilidade, no conhecimento e na intensificação do trabalho, moldou a ecologia histórica destas paisagens e os desafios que estas comunidades enfrentam hoje. Neste sentido a floresta maia depende hoje, mais do que nunca, do agricultor da roça de floresta, para poder renovar-se e sustentar a biodiversidade.

Novos modelos produtivos empresariais e intensivos, baseados no desmatamento, não apenas ameaçam os conhecimentos dos agricultores florestais indígenas, mas ameaçam a própria floresta, ao interromper o seu ciclo de regeneração.

O processo de derrubada, queimada, plantação e posterior abandono das capoeiras permite o repouso e a recuperação da terra. Os agricultores tradicionais cultivam milho por cerca de quatro anos consecutivos no mesmo local. O período entre as plantações de milho (o chamado período de descanso ou abandono) é agora reconhecido por agroecologistas como algo importante para o manejo da terra e da floresta. Estes períodos de descanso dificilmente representam um recuo ou o abandono da terra. São cruciais para o seu manejo, pois facilitam a fertilidade do solo, a conservação da água e a manutenção da biodiversidade.

O sistema de ciclos de roças é completado com etapas de reflorestamento gerenciadas pelos indígenas, o qual implica em seleção de espécies, assim como adaptação das mesmas. Dessa forma, um ciclo total mínimo de abertura e 
reflorestamento de uma área de roça pode levar de 16 a 18 anos. Este é o tempo em que o lugar onde houve roça se torna uma nova floresta densa.

Trata-se de obra importantíssima, pois contribui para pensar a floresta através da visão tradicional dos índios maias, trazendo à tona práticas milenares de sustentabilidade que ajudam a preservar florestas até os dias de hoje.

Recebida em: 07/12/2017 Aprovada em: 04/03/2018

Universidade do Estado de Santa Catarina - UDESC Centro de Ciências Humanas e da Educação - FAED

Revista PerCursos Volume 19 - Número 39 - Ano 2018 revistapercursos@gmail.com 